\title{
ARTICLE The oncometabolite 2-hydroxyglutarate inhibits microglial activation via the AMPK/mTOR/NF-kB pathway
}

\author{
Chao-jun Han ${ }^{1}$, Ji-yue Zheng ${ }^{1}$, Lin Sun ${ }^{1}$, Hui-cui Yang ${ }^{1}$, Zhong-qiang Cao ${ }^{1}$, Xiao-hu Zhang ${ }^{1}$, Long-tai Zheng ${ }^{1}$ and Xue-chu Zhen ${ }^{1}$
}

\begin{abstract}
Microglia, the brain-resident macrophage, is known as the innate immune cell type in the central nervous system. Microglia is also the major cellular component of tumor mass of gliomas that plays a key role in glioma development. Mutations of isocitrate dehydrogenases 1 and 2 (IDH1/2) frequently occur in gliomas, which leads to accumulation of oncometabolic product 2hydroxyglutarate $(2 \mathrm{HG})$. Moreover, IDH1/2 mutations were found to correlate with better prognosis in glioma patients. In the present study, we investigated the effects of the $2 \mathrm{HG}$ on microglial inflammatory activation. We showed that the conditioned media (CM) from GL261 glioma cells stimulated the activation of BV-2 microglia cells, evidenced by markedly increased expression of interleukin-6 (IL-6), IL-1 $\beta$, tumor necrosis factor-a (TNF- $\alpha$ ), CCL2 (C-C motif chemokine ligand 2) and CXCL10 (C-X-C motif chemokine 10). CM-induced expression of proinflammatory genes was significantly suppressed by pretreatment with a synthetic cell-permeable 2HG (1 mM) or a nuclear factor-KB (NF-KB) inhibitor BAY11-7082 (10 $\mu \mathrm{M})$. In lipopolysaccharide (LPS)- or TNF-astimulated BV-2 microglia cells and primary microglia, pretreatment with $2 \mathrm{HG}(0.25-1 \mathrm{mM})$ dose-dependently suppressed the expression of proinflammatory genes. We further demonstrated that $2 \mathrm{HG}$ significantly suppressed LPS-induced phosphorylation of I $\mathrm{KB}$ kinase $\alpha / \beta(\mathrm{IKKa} / \beta)$, IKBa and $\mathrm{p} 65$, I $\mathrm{KB}$ degradation, and nuclear translocation of p65 subunit of NF- $\mathrm{KB}$, as well as NF- $\mathrm{KB}$ transcriptional activity. Similarly, ectopic expression of mutant isocitrate dehydrogenase 1 (IDH1) (R132H) significantly decreased TNF-a-induced activation of NF-KB signaling pathway. Finally, we revealed that activation of adenosine $5^{\prime}$-monophosphateactivated protein kinase (AMPK) and subsequent inhibition of mammalian target of rapamycin (mTOR) signaling contributed to the inhibitory effect of $2 \mathrm{HG}$ on NF-KB signaling pathway in BV-2 cells. Taken together, these results, for the first time, show that oncometabolite $2 \mathrm{HG}$ inhibits microglial activation through affecting AMPK/mTOR/NF-KB signaling pathway and provide evidence that oncometabolite $2 \mathrm{HG}$ may regulate glioma development via modulating microglial activation in tumor microenvironment.
\end{abstract}

Keywords: microglia; glioma; oncometabolite; 2-Hydroxyglutarate; BAY11-7082; inflammation; NF-KB; AMPK; mTOR

Acta Pharmacologica Sinica (2019) 40:1292-1302; https://doi.org/10.1038/s41401-019-0225-9

\section{INTRODUCTION}

Malignant glioma is the most common and aggressive primary tumor of the central nervous system [1, 2]. Glioma is often infiltrated or surrounded by various non-tumor cells, including stromal cells, vascular cells, and infiltrating and resident immune cells, which constitute the glioma microenvironment. Based on substantial evidence, the tumor microenvironment dramatically influences glioma development, including initiation, growth, invasion, and metastasis [3]. Among the tumor-infiltrating nonneoplastic components in the tumor microenvironment of gliomas, the major cell types are microglia/macrophages, which are defined as tumor-associated microglia/macrophages (TAMs) [4]. Macrophages derived from blood monocytes promote cell growth in the late stage of glioma, whereas microglia is indispensable for tumor initiation in the early stage of glioma [5]. The extent of microglia/ macrophage infiltration positively correlates with malignancy and a poor prognosis for patients [6]. The depletion of microglia/ macrophages or inhibition of their accumulation/activation markedly inhibits the progression of gliomas in vivo [7].
Microglia, the resident macrophage of the brain, is the innate immune cell in the central nervous system and a major cellular component of the glioma tumor mass [3]. Microglial activation is often observed in response to neuronal injuries or glioma [8], and activated microglia produce a variety of proinflammatory mediators, such as tumor necrosis factor- $a$ (TNF- $\alpha$ ), chemokines, prostaglandin E2 (PGE2), interleukin-1 $\beta$ (IL-1 $\beta$ ), IL-6, reactive oxygen species and matrix metalloproteinases (MMPs). These proinflammatory mediators are also expressed in gliomaassociated microglia [4, 5, 9-13]. Although classically activated microglia is believed to exert cytotoxic effects on neuronal cells or glioma cells, they also produce growth factors that promote cell survival, growth, and metastasis [14]. TAMs in glioma exhibit alternative macrophage activation and express M2 (anti-inflammatory) markers [4]. Notably, the polarization of microglia/ macrophages is based on in vitro observations. Researchers have long discussed whether polarization indeed occurs in vivo [15]. Recently, TAMs in glioma were reported to only partially overlap with the M1 and M2 phenotypes in terms of the gene expression

\footnotetext{
${ }^{1}$ Jiangsu Key Laboratory of Neuropsychiatric Diseases and College of Pharmaceutical Sciences, Soochow University, Suzhou 215123, China Correspondence: Long-tai Zheng (zhenglongtai@suda.edu.cn) or Xue-chu Zhen (zhenxuechu@suda.edu.cn)

These authors contributed equally: Chao-jun Han, Ji-yue Zheng.
}

Received: 5 November 2018 Accepted: 26 February 2019

Published online: 23 April 2019 
patterns [16]. Therefore, the state of activated microglia in glioma and their roles in glioma progression remain controversial.

$\mathrm{IDH}$ is an enzyme that catalyzes the oxidative decarboxylation of isocitrate to produce a-ketoglutarate $(\mathrm{a}-\mathrm{KG})$ and $\mathrm{CO}_{2}$. Somatic mutations in IDH1 (R132) and IDH2 (R172) have been identified in multiple human cancers, including glioma and acute myeloid leukemia [17-19]. The IDH1 (R132) mutation occurs in $>80 \%$ of World Health Organization grade II-III and secondary glioblastomas [17]. In addition to abolishing the production of a-KG, IDH1/ $\mathrm{IDH} 2$ mutations increase the enzymatic activity and convert $\mathrm{a}-\mathrm{KG}$ to the structurally similar molecule 2-hydroxyglutarate (2HG) [20]. As a close analog of $\mathrm{a}-\mathrm{KG}, 2 \mathrm{HG}$ plays an important role in tumorigenesis by competitively inhibiting activity of a-KGdependent dioxygenases, prolyl hydroxylase, histone demethylases, and the Ten-Eleven Translocation family of 5-methylcytosine hydroxylases [21, 22]. Elevated levels of $2 \mathrm{HG}$ in the serum or urine of patients with various malignancies have also been reported [23-25]. In IDH1 mutant glioma cells, $2 \mathrm{HG}$ accumulates in the cell culture medium $[20,26]$. Interestingly, patients with glioma harboring IDH1/IDH2 mutations have a longer survival time than patients without IDH mutants [20, 22]. Although several mechanisms have been proposed to determine the differences in survival time between these two types of patients, the IDH mutantinduced alterations in the tumor microenvironment might be particularly important. An IDH1 mutant mouse glioma model and clinical specimens of glioma tissues show a reduction in inflammatory cell infiltration, neutrophil chemotaxis [27], and $\mathrm{CD}^{+} \mathrm{T}$ cell accumulation, as well as suppressed expression of cytotoxic T lymphocytes-attracting chemokines [28]. Based on these results, the oncometabolite $2 \mathrm{HG}$ might be involved in modulating the tumor microenvironment by regulating the inflammatory process in gliomas.

Here, we report the effect of the oncometabolite 2HG on the inflammatory activation of microglia. Notably, 2HG inhibits LPSand TNF-a-stimulated production of inflammatory mediators in microglia. In particular, $2 \mathrm{HG}$ regulates the inflammatory activation of microglia through the adenosine $5^{\prime}$-monophosphate-activated protein kinase/mammalian target of rapamycin/nucelar factor-kB (AMPK/mTOR/NF-KB) signaling pathway.

\section{MATERIALS AND METHODS}

\section{Reagents and antibodies}

Bacterial lipopolysaccharide (LPS) (Escherichia coli serotype 055: B5) and 3-(4,5-dimethylthiazol-2-yl)-2,5-diphenyltetrazolium bromide (MTT) were obtained from Sigma-Aldrich (St. Louis, MO, USA) and dissolved in phosphate-buffered saline (PBS; 150 $\mathrm{mM} \mathrm{NaCl}, 5 \mathrm{mM}$ phosphate, $\mathrm{pH}$ 7.4). Recombinant human TNF-a (C036) was purchased from Novoprotein (Shanghai, China). Cellpermeable 1-octyl-R-2HG (octyl-R-2HG) was synthesized as previously described [29]. The stock solution of octyl-R-2HG $(1 \mathrm{~mol} / \mathrm{L})$ was dissolved in dimethyl sulfoxide. Lipofectamine 2000 (11668019) was purchased from Invitrogen (Carlsbad, CA, USA). Metformin (S1950), Compound C (S7306), and rapamycin (S1039) were purchased from Selleck (Houston, TX, USA). The antibodies against inducible nitric oxide synthase (ab15323) and cyclooxygenase-2 (COX-2) (ab62331) were obtained from Abcam (Cambridge, MA, USA). The antibodies against IKKa/ $\beta$ (2078S), IKKß (8943S), IKBa (4814S), phosphorylated (p)-IKBa (2859S), p65 (8242S), p-p65 (Ser536, 3033S), AMPK (2532S), p-AMPK (Thr172, 2535 S), mTOR (2972 S), p-mTOR (Ser2448, 2971S), p70 S6K (Thr389, 9202S), p-p70 S6K (9206S), S6 (2217S), p-S6 (Ser235/ $236,4856 \mathrm{~S})$, and Lamin B (13435 S) were purchased from Cell Signaling Technology (Danvers, MA, USA). The anti-a-Tubulin antibody (T6199) was obtained from Sigma-Aldrich, and the anti-IL-1 $\beta$ (GTX74034) and anti-TNF-a (BAF410) antibodies were supplied by GeneTex (Irvine, CA, USA) and R\&D Systems (Minneapolis, MN, USA), respectively.
Cell culture

BV-2 (murine microglia, RRID: CVCL_0182) and GL261 (murine glioma, RRID: CVCL_Y003) cell lines and HEK293T (human embryonic kidney, RRID: CVCL_0063) were purchased from The Cell Bank of Type Culture Collection of Chinese Academy of Sciences (Shanghai, China). These cells were maintained in Dulbecco's modified Eagle's medium (DMEM) (Gibco, Grand Island, NY, USA) supplemented with $10 \%$ fetal bovine serum in a $37^{\circ} \mathrm{C}$ incubator with a $5 \% \mathrm{CO}_{2}$ atmosphere.

\section{Isolation of mouse primary microglia}

Mouse primary microglial cultures were prepared from neonatal mouse brain tissues using previously described methods, with minor modifications [30]. First, the chopped cerebral cortices of newborn C57BL/6 mice were digested with papain (Sigma-Aldrich) and DNase I (Sigma-Aldrich) and filtered through a $40 \mu \mathrm{m}$ cell strainer. Then, the dissociated cells were collected by centrifugation, seeded in poly-D-lysine-coated F12 (Gibco/F12 (Gibco, New York City, NY, USA) at $37^{\circ} \mathrm{C}$ for 14 days. The mixed glial cells were shaken at $180 \mathrm{r} / \mathrm{min}$ for $6 \mathrm{~h}$ at $37^{\circ} \mathrm{C}$ to isolate and collect microglial cells. These microglial cells were cultured in the medium for the MTT assay or enzyme-linked immunosorbent assay. C57BL/6J mice were obtained from the Shanghai Laboratory Animal Center, Chinese Academy of Sciences (Shanghai, China). All animal experiments were conducted in accordance with the guidelines for care and use of laboratory animals from the $\mathrm{NIH}$ using a protocol approved by the Institutional Review Board of Soochow University.

\section{MTT assay}

Cytotoxicity was determined using the MTT assay. Cells were seeded in 96-well plates in triplicate at a density of $2 \times 10^{4}$ cells/ well. After a $24 \mathrm{~h}$ drug incubation, the culture medium was discarded, $30 \mu \mathrm{L}$ of $0.5 \% \mathrm{MTT}$ reagent was added to each well, and the plate was incubated for $4 \mathrm{~h}$ at $37^{\circ} \mathrm{C}$. One hundred microliters of dimethyl sulfoxide (DMSO) were added to dissolve the formazan crystals, and the absorbance was measured at $570 \mathrm{~nm}$ using a Multiscan MK3 plate reader (Thermo Fisher Scientific, Waltham, MA, USA).

Enzyme-linked immunosorbent assay

Culture supernatants of BV-2 cells were collected after stimulation. Levels of secreted TNF-a, IL-6, and PGE2 were detected according to the manufacturer's instructions (ELISA development reagents, R\&D Systems, Minneapolis, MN, USA) and our previous reports [31, 32]. The standard and samples were added to the antibody-coated 96-well plates $(100 \mu \mathrm{L} /$ well) and incubated at room temperature for $2 \mathrm{~h}$. Then, the plates were washed with PBST five times and patted on a filter paper. After the addition of $100 \mu \mathrm{L}$ of the biotinylated complex to each well and an incubation for $1 \mathrm{~h}$, the plate was washed with PBST five times. One hundred microliters of the horseradish peroxidase-labeled avidin complex was added and incubated at room temperature for $1 \mathrm{~h}$ before five washes with PBST. One hundred microliters of enzyme reaction substrate were added and incubated for $30 \mathrm{~min}$. The reaction was terminated by the addition of $100 \mu \mathrm{L}$ of $1 \mathrm{~mol} / \mathrm{L}$ sulfuric acid, and then the $O D$ value was measured at $450 \mathrm{~nm}$ using a microplate reader.

\section{Quantitative real-time PCR}

BV-2 cells were cultured in 12-well plates at a density of $1 \times 10^{5}$ cells/well, exposed to different treatments for $6 \mathrm{~h}$, and total RNA was isolated using an RNAiso Plus kit (TaKaRa, Shiga, Japan). The complementary DNA (cDNA) templates were generated from $1 \mu \mathrm{g}$ of total RNA according to the manufacturer's instructions and then used for quantitative reverse transcription as previously reported [33]. The volume of the real-time PCR system was $20 \mu \mathrm{L}$, containing $6 \mu \mathrm{L}$ of sterile distilled water, $500 \mathrm{nM}$ primers $(0.5 \mu \mathrm{L}$ 
of each primer stock), $3 \mu \mathrm{L}$ of the cDNA templates, and $10 \mu \mathrm{L}$ of SYBR Green PCR Master Mix (TaKaRa). The reaction conditions were $30 \mathrm{~s}$ at $95^{\circ} \mathrm{C}$ (pre-denaturation), followed by $5 \mathrm{~s}$ at $95^{\circ} \mathrm{C}$ (denaturation) and $30 \mathrm{~s}$ at $60^{\circ} \mathrm{C}(40$ cycles). Then, the reaction system was heated slowly from $60^{\circ} \mathrm{C}$ to $95^{\circ} \mathrm{C}$ to establish the melting curve after the amplification reaction. Glyceraldehyde 3phosphate dehydrogenase (GAPDH) was used to normalize the data as a control, and normalized values were subjected to the $2^{-\triangle \triangle \mathrm{Ct}}$ formula to calculate the change in expression between the experimental groups and the control. PCR was performed on a StepOnePlus $^{\text {TM }}$ Real-Time PCR System (Applied Biosystems, Carlsbad, CA, USA). The nucleotide sequences of specific primers are shown in Table 1.

NF-kB reporter assay

BV-2 microglia cells stably expressing an NF-KB reporter lentiviral construct were established as previously described [34]. The NF-KB-expressing BV-2 cells were cultured in 12-well plates in triplicate and stimulated with LPS for $6 \mathrm{~h}$ after a pretreatment with or without the compounds for $30 \mathrm{~min}$. Then, a luciferase assay kit (Promega, Madison, WI, USA) was used to detect luciferase activity according to the manufacturer's instructions, and promoter activity values are reported in arbitrary units.

Preparation of nuclear and cytosolic fractions

Nuclear and cytosolic fractions were prepared using NE-PER Nuclear and Cytoplasmic Extraction Reagents according to the manufacturer's instructions (Thermo Fisher Scientific). Cells were homogenized and lysed with ice-cold CER I and CER II buffers; then, the supernatants were centrifuged for $5 \mathrm{~min}$ at $1.6 \times 10^{4} \mathrm{~g}$. The cytosolic extracts were collected and stored at $-80^{\circ} \mathrm{C}$. The nuclear pellet was resuspended and incubated with NER buffer for $40 \mathrm{~min}$. The nuclear lysate was centrifuged for $10 \mathrm{~min}$ at $1.6 \times 10^{4}$ $g$ and the fraction containing the soluble nuclear proteins was stored at $-80^{\circ} \mathrm{C}$ until further assay.

\section{Western blotting}

Cells were harvested in RIPA lysis buffer $[150 \mathrm{mM} \mathrm{NaCl}, 50 \mathrm{mM}$ Tris- $\mathrm{HCl}, \mathrm{pH} 8.0,1 \%$ Triton $\mathrm{X}-100,0.5 \%$ sodium deoxycholate, $0.1 \%$ sodium dodecyl sulfate, and protease inhibitor cocktail tablets (Roche, Basel, Switzerland)]. After determining the protein concentration, $40 \mu \mathrm{g}$ of each sample was loaded onto sodium dodecyl sulfate-polyacrylamide gel electrophoresis gels, electrophoresed, and transferred to $0.2 \mu \mathrm{m}$ polyvinylidene difluoride membranes (Millipore, Billerica, MA, USA). Membranes were blocked with $5 \%$ non-fat milk in Tris-buffered saline (TBS) for $2 \mathrm{~h}$, and then exposed to specific primary antibodies and the a-tubulin antibody (Sigma-Aldrich) overnight at $4{ }^{\circ} \mathrm{C}$. The membranes were then incubated with secondary antibodies (Sigma-Aldrich) after three washes with TBS containing $0.1 \%$ Tween-20 (Sigma-Aldrich) (TBST). A ChemiScope 3300 Mini (CLINX, Shanghai, China) instrument was used to visualize the protein bands according to the manufacturer's instructions.

\section{Metabolic assays}

BV-2 cells were cultured in 12-well plates at a density of $1 \times 10^{5}$ cells/well. The ATP/ADP Assay Kit (Sigma-Aldrich) was used to calculate the ATP/ADP ratio according to the standard protocol. For the analysis of the oxygen consumption rate (OCR), cells were plated in the XF-24 cell culture microplates at a density of $2 \times 10^{4}$ cells/well and incubated at $37^{\circ} \mathrm{C}$ in a $5 \% \mathrm{CO}_{2}$ atmosphere for $24 \mathrm{~h}$. After $12 \mathrm{~h}$ of hydration in a $37^{\circ} \mathrm{C}$ non- $\mathrm{CO}_{2}$ incubator, the XF-24 analyzer sensor cartridge and microplates were carefully snapped together. The initial OCR of BV-2 cells was assayed using the XF-24 Extracellular Flux Analyzer (Seahorse Bioscience, City of Santa Clara, CA, USA). The OCR was recorded every $10 \mathrm{~min}$ using the analyzer [35].
Table 1. DNA sequences of the primers used for RT-PCR

\begin{tabular}{|c|c|}
\hline CDNA & Primer sequences \\
\hline GAPDH & $\begin{array}{l}\text { Forward primer: } 5^{\prime} \text {-TGTGTCCGTCGTGGATCTGA-3' } \\
\text { Reverse primer: } 5^{\prime} \text {-TTGCTGTTGAAGTCGCAGGAG-3' }\end{array}$ \\
\hline IL-6 & $\begin{array}{l}\text { Forward primer: } 5^{\prime} \text {-TTCCATCCAGTTGCCTTCTT-3' } \\
\text { Reverse primer: } 5^{\prime} \text {-CAGAATTGCCATTGCACAAC-3' }\end{array}$ \\
\hline IL-1 $\beta$ & $\begin{array}{l}\text { Forward primer: 5'-TCCAGGATG AGGACATGAGCAC-3' } \\
\text { Reverse primer: } \text { 5'-GAACGTCACACACCAGCAGGTTA-3' }^{\prime}\end{array}$ \\
\hline TNF- $\alpha$ & $\begin{array}{l}\text { Forward primer: 5'-CATCTTCTCAAAATTCGAGTGACA-3' } \\
\text { Reverse primer: } 5^{\prime} \text {-TGGGAGTAGACAAGGTACAACCC- } 3^{\prime}\end{array}$ \\
\hline $\operatorname{cox}-2$ & $\begin{array}{l}\text { Forward primer: } 5^{\prime} \text {-CAGGCTGAACTTCGAAACA-3' } \\
\text { Reverse primer: } 5^{\prime} \text {-GCTCACGAGGCCACTGATACCTA-3' }\end{array}$ \\
\hline CCL2 & $\begin{array}{l}\text { Forward primer: 5'- TTAAAAACCTGGATCGGAACCAA-3' } \\
\text { Reverse primer: } 5^{\prime} \text { - GCATTAGCTTCAGATTTACGGGT-3' }\end{array}$ \\
\hline CXCL10 & $\begin{array}{l}\text { Forward primer: } 5^{\prime} \text {-CCAAGTGCTGCCGTCATTTTC- } 3^{\prime} \\
\text { Reverse primer: } 5^{\prime} \text {-GGCTCGCAGGGATGATTTCAA-3' }\end{array}$ \\
\hline MMP2 & $\begin{array}{l}\text { Forward primer: 5'-CAAGTTCCCCGGCGATGTC-3' } \\
\text { Reverse primer: } 5^{\prime} \text {-TTCTGGTCAAGGTCACCTGTC-3' }\end{array}$ \\
\hline MMP14 & $\begin{array}{l}\text { Forward primer: } 5^{\prime} \text {-CAGTATGGCTACCTACCTCCAG-3' } \\
\text { Reverse primer: } 5^{\prime} \text {-GCCTTGCCTGTCACTTGTAAA-3' }\end{array}$ \\
\hline \multicolumn{2}{|c|}{$\begin{array}{l}R T-P C R \text { reverse transcription polymerase chain reaction, GAPDH glycer- } \\
\text { aldehyde } 3 \text {-phosphate dehydrogenase, IL interleukin, TNF- } a \text { tumor necrosis } \\
\text { factor- } \alpha, C O X-2 \text { cyclooxygenase- } 2, C C L 2 \text { C-C motif chemokine ligand } 2, M M P \\
\text { matrix metalloproteinase }\end{array}$} \\
\hline
\end{tabular}

Statistical analysis

All results are presented as the means \pm standard deviations. The statistical significance of differences was assessed using GraphPad software version 6.0 (GraphPad Software, Inc., La Jolla, CA, USA). Student's $t$ test was used to compare data between two groups. For comparisons between multiple groups, one-way analysis of variance (ANOVA) or two-way ANOVA followed by Bonferroni's post hoc test were utilized. A $P$ value $<0.05$ was considered statistically significant.

\section{RESULTS}

2HG inhibits LPS- or TNF-a-triggered microglial activation $R-2 \mathrm{HG}$ was shown to accumulate to levels up to $\sim 5-35 \mu \mathrm{mol} / \mathrm{g}$ in $I D H$-mutated glioma tumors $[20,36]$, and an liquid chromatographymass spectrometry analysis indicated that the microenvironment of an IDH1 mutant glioma was likely exposed to high concentrations of $2 \mathrm{HG}$ in the low millimolar range [37]. The synthetic cellpermeable octyl- $R-2 \mathrm{HG}$ compound is usually used to mimic high intracellular concentrations of $R-2 \mathrm{HG}$ in vivo. It is not suitable for the study of microglia because glioma-associated microglia cells are mainly affected by the glioma microenvironment, but the IDH1 ( $\mathrm{R} 132 \mathrm{H})$ mutation was detected in glioma-associated microglia/ macrophages [38]. In addition, the intracellular $R-2 \mathrm{HG}$ concentration in stromal cells was determined using mass spectrometry, and a treatment with $R-2 \mathrm{HG}$ or octyl- $R-2 \mathrm{HG}$ induced a 71 -fold and $250-$ fold increase, respectively, compared with control cells [39, 40]. We initially investigated the effect of conditioned media (CM) from GL261 murine glioma cells on microglial activation to determine the effect of factors secreted from glioma cells on microglial activation, which actively modulate glioma progression. CM from GL261 glioma cells significantly increased the expression of TNF- $\alpha$, IL-1 $\beta$, IL- 6, CCL2 (C-C motif chemokine ligand 2) and CXCL10 (C-X-C motif chemokine 10) on BV-2 microglia cells, and M2 (anti-inflammatory) markers were also up-regulated (Supplementary Fig. 1). Interestingly, the $2 \mathrm{HG}$ treatment significantly suppressed the CM-mediated proinflammatory response in activated BV-2 microglia cells (Fig. 1a). Meanwhile, CM from cultured GL261 glioma cells induced microglial activation through 
a

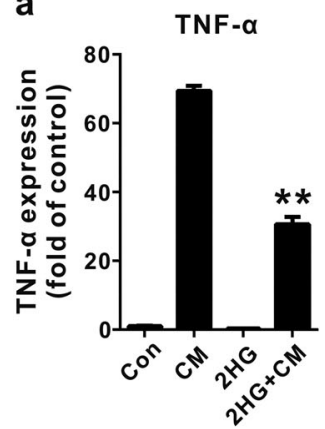

b

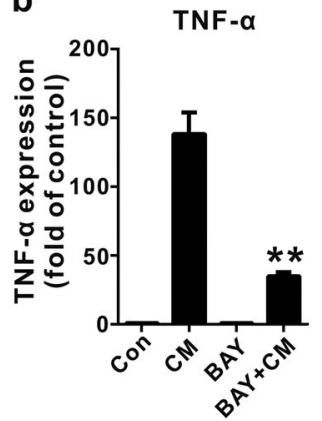

IL-1 $\beta$

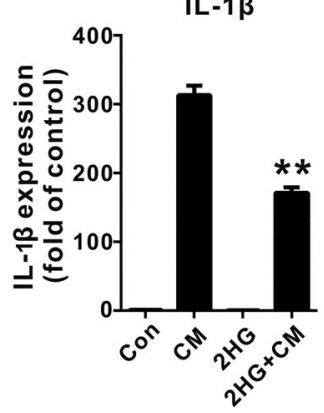

IL-1 $\beta$

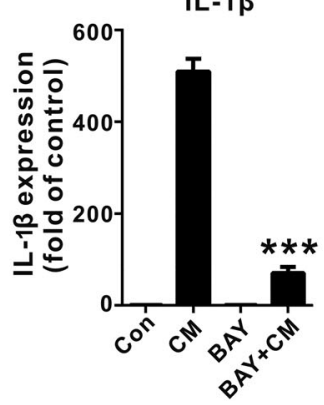

IL-6
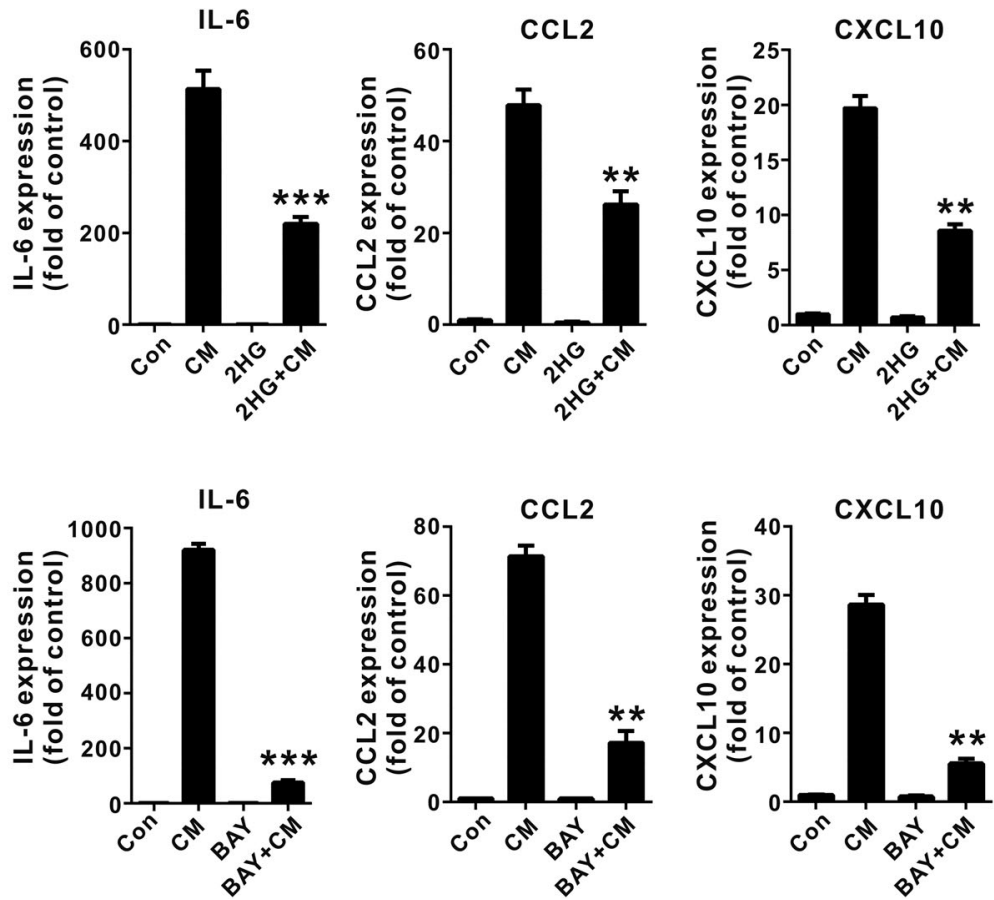

Fig. 1 2-Hydroxyglutarate (2HG) inhibits microglial activation induced by the conditioned media (CM) from GL261 glioma cells. BV-2 cells were pretreated with $1 \mathrm{mM} 2 \mathrm{HG}$ (a) or $10 \mu \mathrm{M}$ BAY-7082 (b) for 30 min. Afterwards, the cells were incubated with CM from GL261 cells for $6 \mathrm{~h}$. The expression of the tumor necrosis factor- $\alpha$ (TNF- $\alpha$ ), interleukin-1 $\beta$ (IL-1 $\beta$ ), IL-6, C-C motif chemokine ligand 2 (CCL2), and C-X-C motif chemokine 10 (CXCL10) messenger RNAs (mRNAs) was determined using quantitative real-time PCR (qPCR), and glyceraldehyde 3-phosphate dehydrogenase (GAPDH) was used as the internal control. All results are presented as the means \pm SD $(n=3)$ and are representative of three or more independent experiments. ${ }^{* *} P<0.01$ and ${ }^{* *} P<0.001$ compared to $C M$

a mechanism dependent on NF-KB activation because the inhibition of NF-KB by BAY11-7082 attenuated proinflammatory gene expression (Fig. 1b). Since toll-like receptor 4 (TLR 4) and tumor necrosis factor receptor (TNFR) are major activators of the NF-kB pathway and key mediators of the glioma-microglia interaction [4], we thus assessed the effect of $2 \mathrm{HG}$ on LPS- or TNF-a-induced microglial activation. As shown in Fig. 2a, b, 2HG strongly suppressed LPS- or TNF-a-induced expression of the TNFa, IL-1 $\beta$, IL-6, MMP2, CCL2, CXCL10, COX-2, and MMP14 (MT1MMP) messenger RNAs (mRNAs) in BV-2 microglia cells in a dosedependent manner, while $2 \mathrm{HG}$ did not alter the viability of BV-2 microglia cells at the tested concentrations (Supplementary Fig. 2). The inhibitory effect of $2 \mathrm{HG}$ on the levels of the TNF- $a, \mathrm{IL}-6, \mathrm{IL}-1 \beta$, and COX-2 proteins in LPS-stimulated BV-2 microglia cells or primary microglia cells was also confirmed using ELISAs or Western blot analyses. 2HG significantly inhibited the production of the IL-1 $\beta$, COX-2, TNF- $\alpha$, and IL- 6 proteins in LPS-stimulated BV2 microglia or primary microglia cells (Fig. $3 a-c)$. Based on these results, $2 \mathrm{HG}$ inhibited the inflammatory activation of microglia.

2HG attenuates the LPS-induced activation of the NF-KB signaling pathway in microglial cells

We next assessed whether 2HG-induced inhibition of microglial activation is mediated via the inhibition of the NF-KB pathway. As shown in Fig. $4 \mathrm{a}$, the $2 \mathrm{HG}$ treatment indeed suppressed LPSinduced activation of NF-KB luciferase activity. In support of this finding, the $2 \mathrm{HG}$ treatment markedly inhibited the LPS-induced phosphorylation of $\mathrm{IKKa} / \beta, \mathrm{I} \mathrm{KBa}$ and $\mathrm{p} 65$, IKB degradation, and nuclear translocation of the p65 subunit of NF-KB (Fig. 4c, d). We transfected the IDH1R132H plasmid into HEK293T cells stably expressing an NF-KB luciferase reporter construct and measured the activation of the NF-KB signaling pathway in response to a TNF-a treatment to determine the effect of the accumulation of endogenous $2 \mathrm{HG}$ on the transcriptional activity of NF-KB (Fig. 4b). Overexpression of IDH1R132H significantly reduced TNF-ainduced NF-kB luciferase activity. Thus, the anti-inflammatory mechanism of $2 \mathrm{HG}$ in microglia cells involved the inhibition of the NF-KB signaling pathway.

$2 \mathrm{HG}$ activates AMPK by altering the ATP/ADP ratio in microglial cells

Previously, 2HG was reported to decrease the ATP/ADP ratio by inhibiting ATP synthase [41]. In addition, the decreased ATP/ADP ratio results in AMPK activation and subsequently negatively regulates NF-KB activation [42]. We next assessed whether $2 \mathrm{HG}$ decreased the ATP/ADP ratio in microglial cells to elucidate the upstream signaling pathway responsible for 2HG-mediated inhibition of NF-KB. As shown in Fig. 5a, the $2 \mathrm{HG}$ treatment significantly decreased the ATP/ADP ratio in both control and activated BV-2 microglial cells in a dose-dependent manner. We next investigated the effect of $2 \mathrm{HG}$ on mitochondrial oxidative phosphorylation (OXPHOS) in BV-2 microglial cells and found that $2 \mathrm{HG}$ significantly decreased the OCRs in both basal and LPSactivated microglia cells in a dose-dependent manner (Fig. 5b). Furthermore, in coordination with the decrease in the ATP/ADP ratio, $2 \mathrm{HG}$ dose-dependently activated AMPK in BV-2 cells, and the $2 \mathrm{HG}$ treatment also blocked the LPS-mediated inhibition of AMPK activation (Fig. 5c, d). Moreover, pretreatment of BV-2 cells with the AMPK-selective inhibitor Compound C (Fig. 5e) or with small interfering RNA (siRNA)-mediated knockdown of AMPK (Supplementary Fig. 3) abolished the anti-inflammatory effect of $2 \mathrm{HG}$ in response to LPS. When ATP synthase (ATP5B) was silenced, LPSinduced expression of the IL-1 $\beta$, TNF- $\alpha, I L-6$, and COX- 2 mRNAs was also decreased, as shown in Supplementary Fig. 4. Based on these results, altered ATP/ADP ratio-mediated AMPK activation was involved in the anti-inflammatory mechanism of $2 \mathrm{HG}$. 

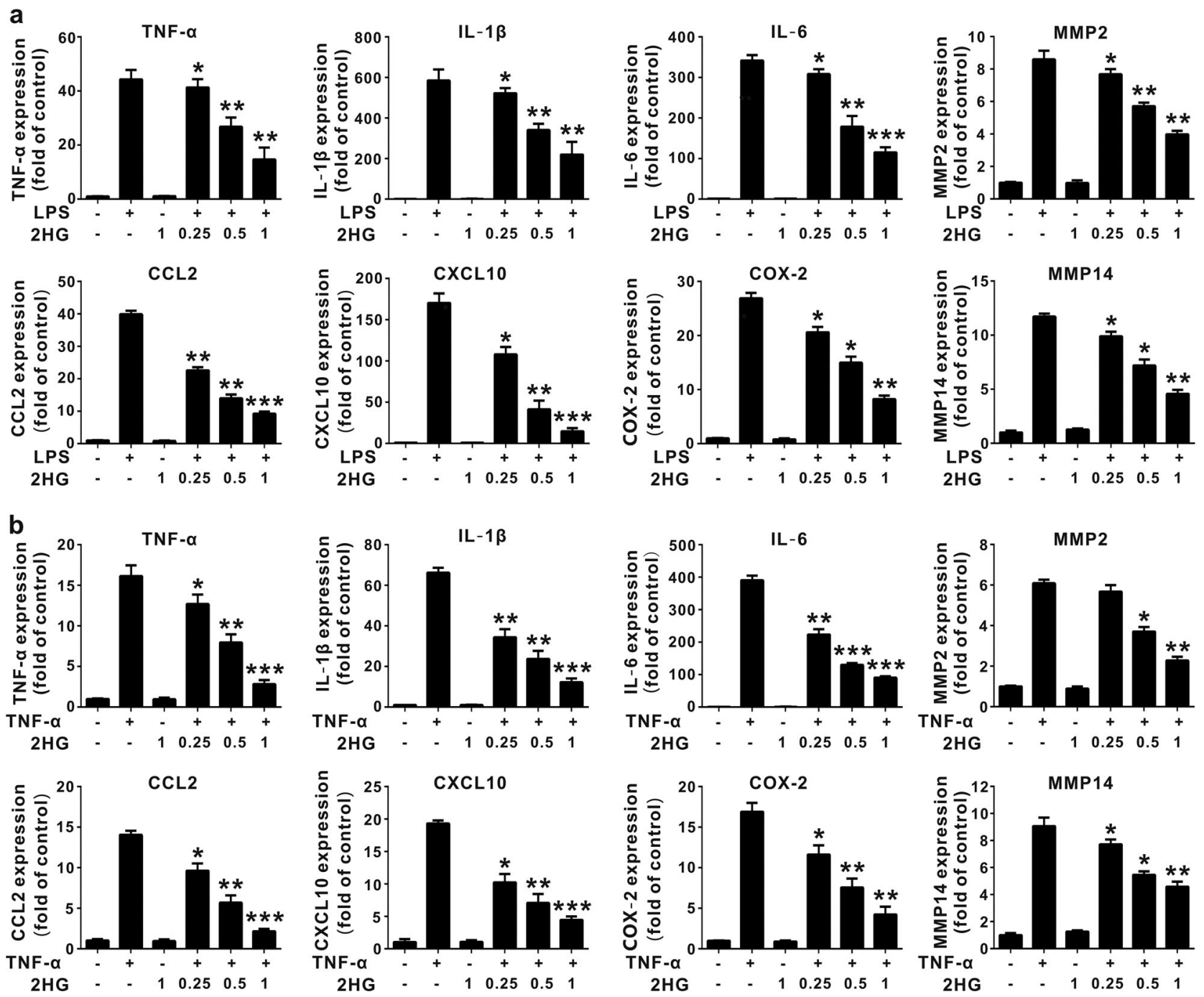

Fig. 2 2-Hydroxyglutarate (2HG) inhibits lipopolysaccharide (LPS)- and tumor necrosis factor- $\alpha$ (TNF- $\alpha$ )-triggered expression of inflammatory cytokine messenger RNAs (mRNAs) in microglial cells. BV-2 cells were incubated with LPS (100 ng/mL) or TNF- $\alpha(10 \mathrm{ng} / \mathrm{mL})$ for the indicated times after a $30 \mathrm{~min} 2 \mathrm{HG}(1 \mathrm{mM})$ pretreatment. a, b BV-2 cells were stimulated with LPS and TNF- $\alpha$ for $6 \mathrm{~h}$, and the expression of the TNF- $\alpha$, interleukin-1 $\beta$ (IL-1 $\beta$ ), IL-6, matrix metalloproteinase 2 (MMP2), C-C motif chemokine ligand 2 (CCL2), C-X-C motif chemokine 10 (CXCL10), cyclooxygenase-2 (COX-2), and MMP14 mRNAs was measured using quantitative real-time PCR (qPCR). Glyceraldehyde 3-phosphate dehydrogenase (GAPDH) was used as the internal control. All results are presented as the means \pm SD $(n=3)$ and are representative of three independent experiments. ${ }^{*} P<0.05$, ${ }^{* *} P<0.01$, and ${ }^{* * *} P<0.001$ compared to LPS or TNF- $\alpha$

2HG inhibits mTOR/IKK-mediated microglial activation via the activation of AMPK

Inhibition of OXPHOS or activation of AMPK decreases mTOR activity, which has been reported to regulate IKK/NF-KB activation $[43,44]$. The $2 \mathrm{HG}$ treatment inhibited both basal and LPS-induced phosphorylation of mTOR and its downstream molecules, including p70 S6K and S6 (Fig. 6a-c), indicating that $2 \mathrm{HG}$ regulated the mTOR signaling pathway. Since $2 \mathrm{HG}$-regulated NF-KB activity was responsible for its anti-inflammatory effect on BV-2 cells (Fig. 4), we further determined how $2 \mathrm{HG}$-mediated regulation of mTOR activity contributes to the inhibition of LPS-induced IKK activation. As shown in Fig. $6 \mathrm{~d}$, e, inhibition of mTOR by rapamycin or activation of AMPK by metformin significantly inhibited LPSstimulated IL-1 $\beta$, IL- 6 , TNF- $\alpha$, and COX-2 expression in BV-2 microglial cells. Meanwhile, rapamycin also markedly suppressed LPS-induced IKK and IKBa phosphorylation, as well as $\mathrm{IKBa}$ degradation, suggesting that the inhibition of mTOR suppressed IKK activation and the subsequent production of proinflammatory mediators. We further confirmed that AMPK was the upstream molecule in the mTOR pathway since metformin affected both
AMPK and mTOR phosphorylation, while rapamycin only inhibited mTOR phosphorylation in LPS-activated BV-2 microglial cells (Fig. 6f). Thus, 2HG inhibited the NF-KB signaling pathway by activating AMPK and inhibiting mTOR signaling.

\section{DISCUSSION}

In the present study, the oncometabolite 2HG inhibited LPS- and TNF-a-induced microglial activation. CM from GL261 murine glioma cells also significantly induced the activation of microglial cells by increasing the expression of TNF- $\alpha$, IL-1 $\beta, I L-6, C C L 2$, and CXCL10, whereas the $2 \mathrm{HG}$ pretreatment inhibited the production of proinflammatory cytokines. Furthermore, 2HG inhibited LPSmediated activation of the NF-KB signaling pathway by activating AMPK and subsequently inhibiting mTOR (Fig. 7).

IDH1/IDH2 catalyzes the oxidative decarboxylation of isocitrate to $a-K G$. Mutations in the IDH1/IDH2 genes are frequently observed in patients with low-grade glioma and secondary glioblastoma [45]. Tumor-derived IDH1/IDH2 mutations lead to a loss of their normal enzymatic activity, production of $a-K G$, and 
a

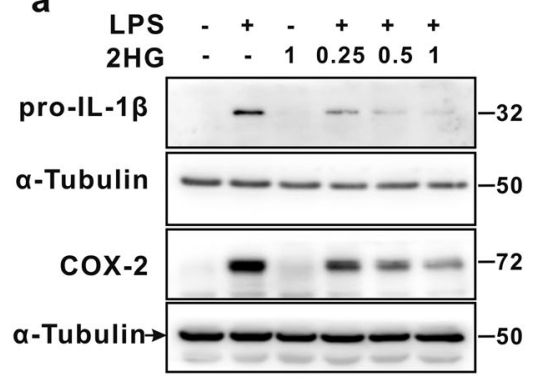

b BV-2 microglia

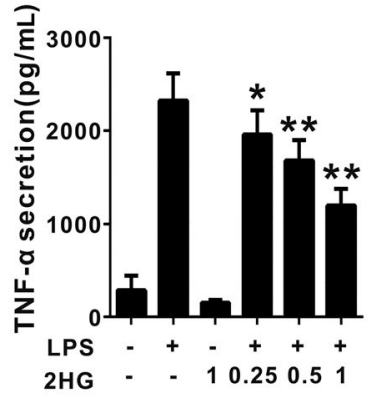

C primary microglia

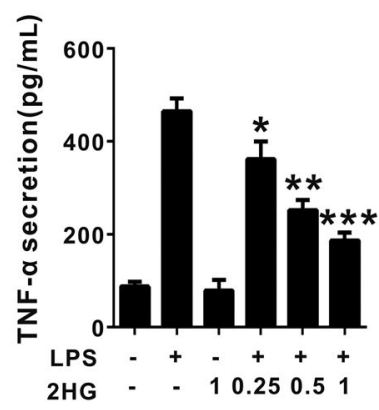

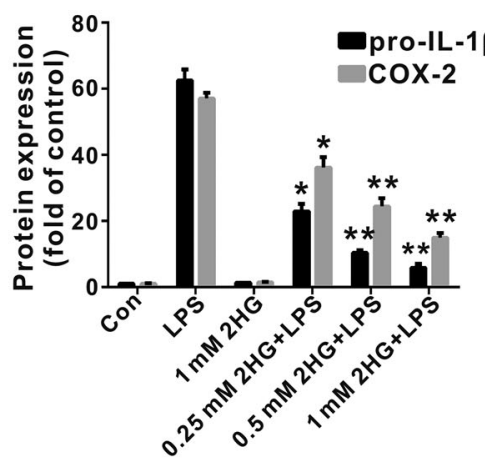

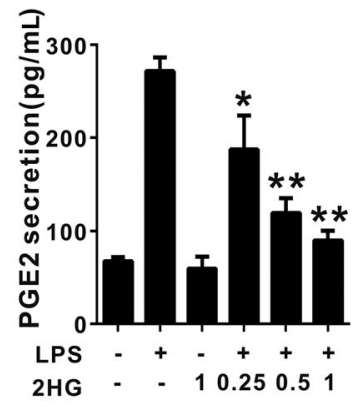

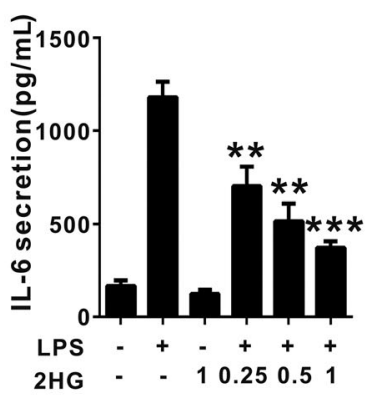

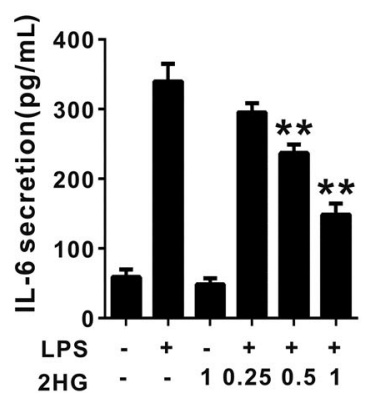

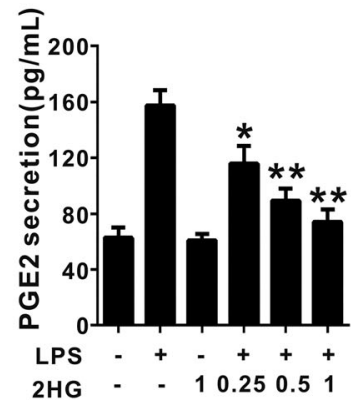

Fig. 3 2-Hydroxyglutarate (2HG) inhibits lipopolysaccharide (LPS)-induced inflammatory cytokine expression in microglial cells. BV-2 cells were incubated with LPS $(100 \mathrm{ng} / \mathrm{mL})$ for the indicated times after a $30 \mathrm{~min} 2 \mathrm{HG}(1 \mathrm{mM})$ pretreatment. a After a $12 \mathrm{~h}$ stimulation with LPS, levels of the pro-interleukin-1 $\beta$ (IL-1 $\beta$ ) and cyclooxygenase-2 (COX-2) proteins were measured using Western blotting. The levels of pro-IL-1 $\beta$ and COX-2 were quantified using densitometry and normalized to $\alpha$-tubulin. $\mathbf{b}$, c The levels of secreted tumor necrosis factor- $\alpha$ (TNF- $\alpha$ ), IL- 6 and prostaglandin E2 (PGE2) in the supernatants of cell lines or primary microglia were measured using enzyme-linked immunosorbent assays (ELISAs). All results are presented as the means $\pm S D(n=3)$ and are representative of three independent experiments. ${ }^{*} P<0.05,{ }^{*} P<0.01$, and $* * * P<0.001$ compared to LPS

the gain of a new function that catalyzes the conversion of $\mathrm{a}-\mathrm{KG}$ to the oncometabolite $2 \mathrm{HG}$ [20]. Elevated levels of $2 \mathrm{HG}$ have been detected in patients' serum, urine, and the extracellular medium of IDH-mutated glioma cells [23-25]. The RNA-sequencing data from clinical samples revealed decreased expression of proinflammatory genes, such as interferon- $\gamma$-inducible genes, $\mathrm{CD}^{+}$-related genes, and chemokines, in IDH1 mutant samples compared to IDH1 wild-type samples [28]. Based on the data from patients carrying mulDH1 and a mouse glioma model, the longer survival time of patients carrying mulDH1 may be associated with the reduced infiltration of tumor-associated immune cells [21]. However, with the exception of the density of glioma-infiltrated microglial cells, researchers have not clearly determined whether the activation status of these cells is affected by $2 \mathrm{HG}$. In the present study, 2HG directly inhibited microglial expression of TNFa, IL-6, IL-1 $\beta$, COX-2, CCL2, and CXCL10 induced by CM from glioma cells or proinflammatory stimuli. The chemokines CCL2 and CXCL10 recruit inflammatory cells to tumor sites [28], whereas proinflammatory cytokines, including IL- 6 , IL-1 $1 \beta$, and TNF-a, create a proinflammatory microenvironment, thereby promoting the malignant transformation and progression of low-grade glioma [4]. Additionally, $2 \mathrm{HG}$ alone did not affect the expression of the classic M2 macrophage/microglia markers Arg1, CD206, and IL-10 (data not shown). Thus, elevated $2 \mathrm{HG}$ levels in glioma might contribute to the anti-inflammatory microenvironment of IDH1/2mutated gliomas and subsequent better prognosis of patients with IDH1/2-mutated glioma.

Although the roles of $2 \mathrm{HG}$ in the tumorigenesis, progression, and therapeutic susceptibility of glioma are rather complex and different, elevated $2 \mathrm{HG}$ levels in IDH1/2-mutated glioma may contribute to tumor formation by affecting cellular metabolism, DNA repair systems, and epigenetic regulation [40]. In addition, based on accumulating clinical evidence, these mechanisms listed below are involved in determining the better prognosis of patients carrying IDH1/2 mutations. (i) First, $2 \mathrm{HG}$ increases the susceptibility of IDH1/2 mutant glioma cells to chemotherapy and irradiation by inhibiting DNA repair enzymes [45, 46], reducing NADPH production [47] and impairing redox systems [48]. (ii) $2 \mathrm{HG}$ reduces the infiltration and inflammatory activation of microglia/ macrophages in glioma tissues, and (iii) $2 \mathrm{HG}$ directly inhibits 

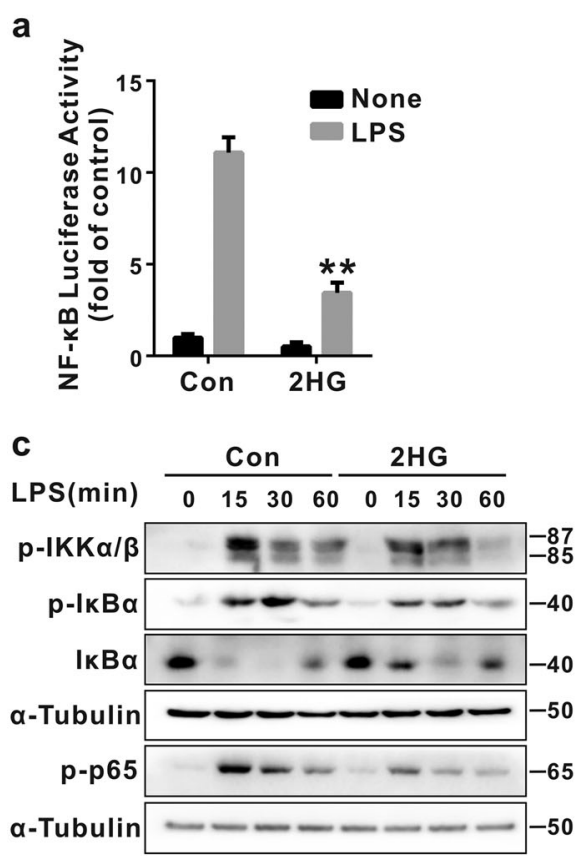

d

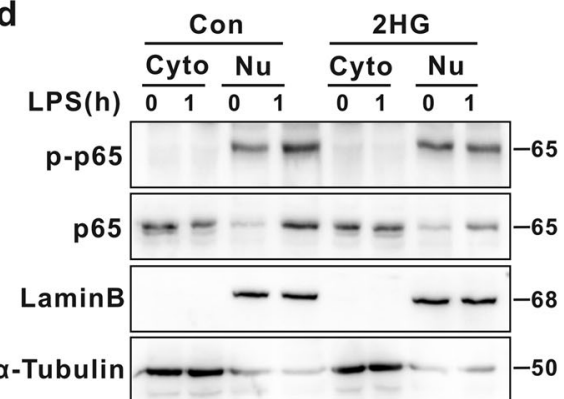

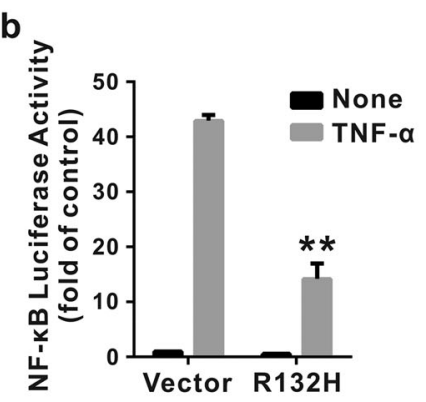
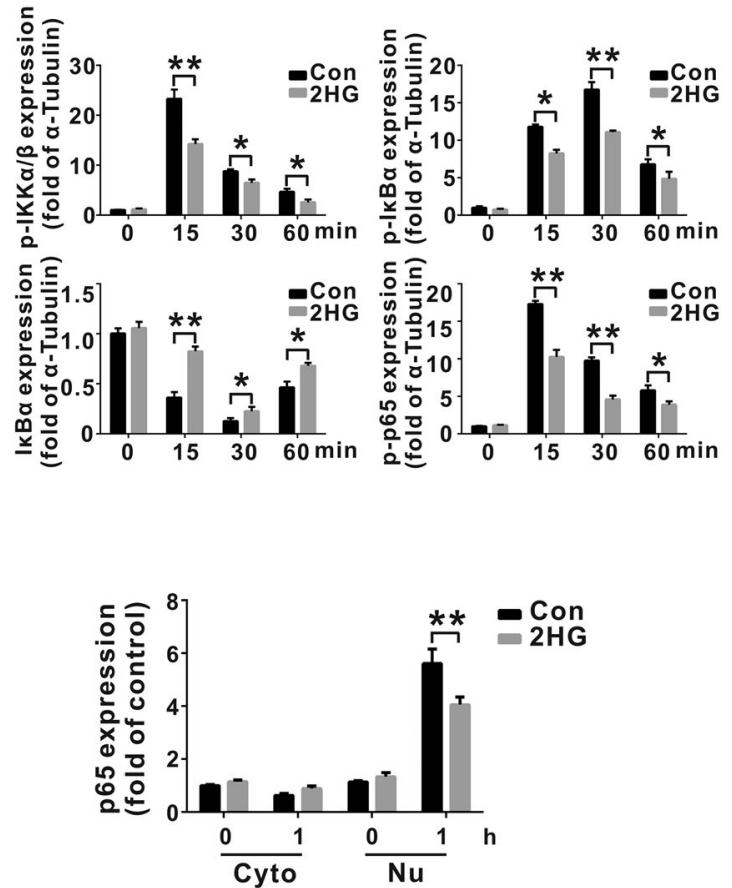

Fig. 4 2-Hydroxyglutarate (2HG) attenuates the lipopolysaccharide (LPS)-induced activation of the nuclear factor- $\kappa B$ (NF- $\kappa B$ ) signaling pathway. a BV-2 cells stably expressing the NF-KB reporter construct were pretreated with $2 \mathrm{HG}$ for 30 min and then incubated with LPS

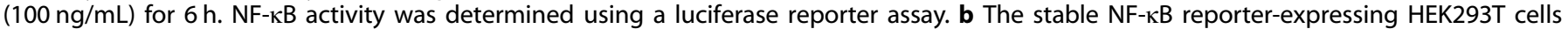
were transfected with the vector or R132H plasmids for $24 \mathrm{~h}$, and then NF-KB luciferase activity was measured after a $6 \mathrm{~h}$ treatment with TNF- $\alpha$ $(10 \mathrm{ng} / \mathrm{mL})$. NF-KB activity is reported as relative values, and the values of the control are set to a relative value of 1 . BV-2 cells were stimulated with LPS $(100 \mathrm{ng} / \mathrm{mL})$ for the indicated times after a $30 \mathrm{~min} 2 \mathrm{HG}(1 \mathrm{mM})$ pretreatment. c The whole-cell lysate and d nuclear and cytosolic fractions were harvested, and the levels of phosphorylated ( $p-$ ) and total proteins were analyzed using Western blotting. $\alpha$-Tubulin was used as an internal control for the whole-cell lysate or cytosolic fractions. Levels of nuclear proteins were quantified using densitometry and normalized to Lamin B. ${ }^{*} P<0.05$ and ${ }^{* *} P<0.01$ compared to Con + LPS or Vector + TNF- $\alpha$. All results are presented as the means \pm SD $(n=3)$ and are representative of three independent experiments

tumor cell growth. Therefore, 2HG accumulation contributes to the oncogenesis of IDH1/2 mutant gliomas, but it may also inhibit the progression of glioma by increasing susceptibility of IDH1/2mutated glioma cells to cytotoxic agents [40]. On the other hand, $2 \mathrm{HG}$ in the tumor environment is taken up by non-cancer cells, including T cells, stromal cells, and NK cells, where it suppresses $\mathrm{T}$ cell- or NK cell-mediated anti-tumor immune responses, indicating that $2 \mathrm{HG}$ production in gliomas carrying the IDH $1 / 2$ mutation exerts a deleterious effect on the efficacy of immunotherapy $[40,49]$. Collectively, results from previous reports and the present study suggest that the oncometabolite $2 \mathrm{HG}$ plays diverse roles in the formation, progression, and therapeutic treatment of $\mathrm{IDH} 1 / 2$-mutated gliomas, and its role in overall glioma prognosis might depend on the disease stage and mode of treatment. The detailed roles of $2 \mathrm{HG}$ in tumorigenesis and therapy require further investigations in future studies.

The NF-KB signaling pathway plays a key role in regulating the expression of proinflammatory genes. Upon binding to LPS or TNF-a, TLR4, or TNFR forms a complex with various molecules, including MyD88, IRAK, and TRAF6, leading to the phosphorylation of $\mathrm{IKK} \beta$ [50]. Activated IKK 3 phosphorylates $\mathrm{IKBa}$ and the p65 subunit of NF-KB, resulting in the transcription of proinflammatory genes [50]. In the present study, 2HG inhibited LPStriggered phosphorylation of $1 \mathrm{KK}, \mathrm{IKBa}$ and $\mathrm{p} 65$, and the degradation of $\mathrm{IKBa}$, leading to the suppression of the transcriptional activity of NF-KB in microglial cells. Previously, 2HG was reported to activate the NF-KB signaling pathway in an IKKindependent manner in bone marrow stromal cells [39]. In the present study, a low dose of $2 \mathrm{HG}$ alone did not affect the activity of NF-KB, suggesting that the effects of $2 \mathrm{HG}$ on NF-KB activation depend on the cell type and concentration of the compound.

AMPK is a central regulator of cellular energy metabolism in eukaryotes [51]. Based on accumulating evidence, AMPK negatively regulates the inflammatory activation of macrophages by inhibiting NF-KB activity [51]. Several proteins are responsible for the inhibitory effects of AMPK on NF-KB activation, including Sirtuin 1 (SIRT1), p53, and PGC-1a [51]. AMPK activates the deacetylase SIRT1, which deacetylates the 


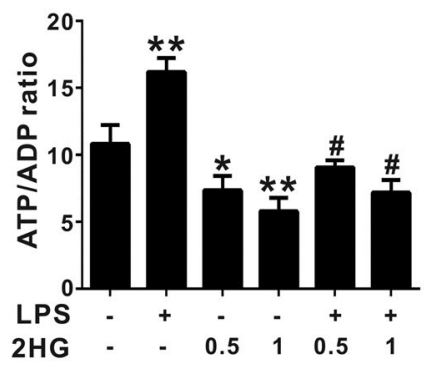

b

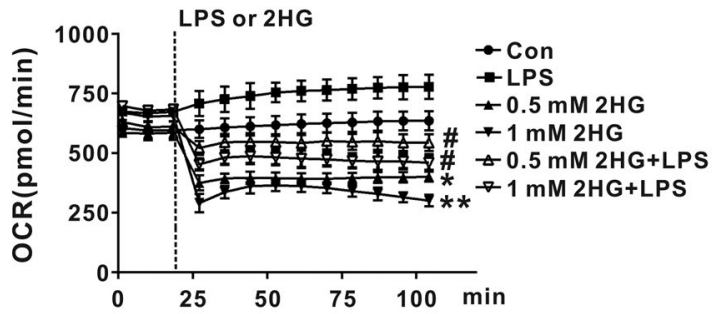

C
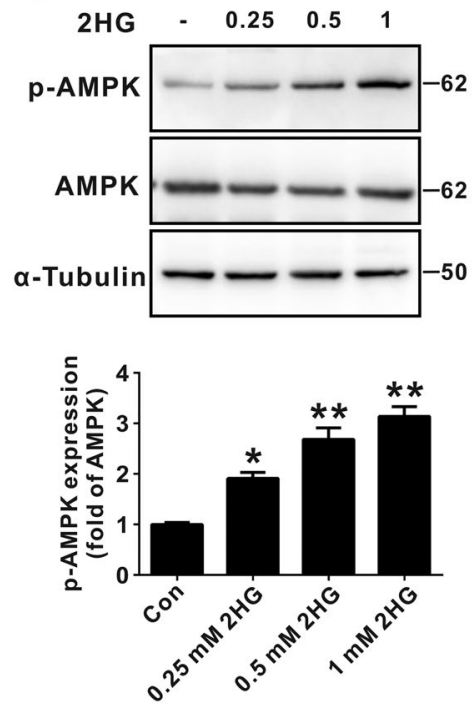

d
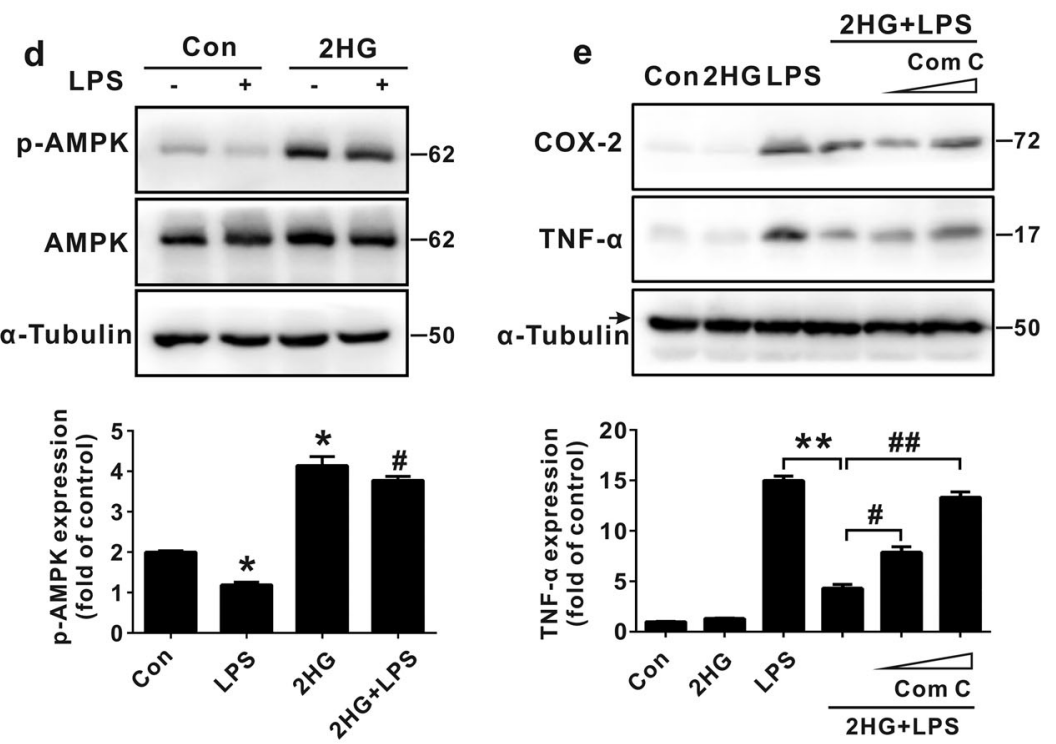

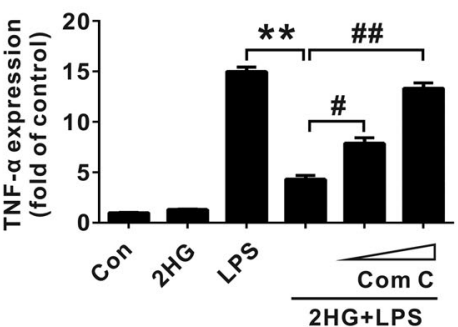

Fig. 5 2-Hydroxyglutarate (2HG) activates adenosine 5'-monophosphate (AMP)-activated protein kinase (AMPK) in microglial cells. a BV-2 cells were incubated with lipopolysaccharide (LPS) $(100 \mathrm{ng} / \mathrm{mL})$ for the indicated times after a $30 \mathrm{~min} 2 \mathrm{HG}(1 \mathrm{mM})$ pretreatment. The ATP/ADP ratio was measured as described in the metabolic assays section. ${ }^{*} P<0.05$ and ${ }^{* *} P<0.01$ compared to Con. ${ }^{\#} P<0.05$ compared to LPS. $\mathbf{b}$ Cells were stimulated with LPS or $2 \mathrm{HG}$, and the LPS-induced initial oxygen consumption rate (OCR) was recorded every 10 min in the XF-24 analyzer. ${ }^{*} P<$ 0.05 and ${ }^{* *} P<0.01$ compared to Con. ${ }^{\#} P<0.05$ and ${ }^{\# \#} P<0.01$ compared to LPS. $c$, d. Cells were treated with LPS or $2 \mathrm{HG}$, and the levels of the indicated phosphorylated ( $p-)$ and total proteins were analyzed using Western blotting. The levels of all proteins were quantified using densitometry and normalized to $\alpha$-tubulin. ${ }^{*} P<0.05$ compared to Con. ${ }^{\#} P<0.05$ compared to LPS. e Cells were pretreated with the AMPK antagonist Compound C (Com C), and the anti-inflammatory effect of $2 \mathrm{HG}$ was partially reversed. ${ }^{* *} P<0.01$ compared to LPS. ${ }^{\#} P<0.05$ and ${ }^{\# \#} P<0.01$ compared to $2 \mathrm{HG}+$ LPS. All results are presented as the means \pm SD $(n=3)$ and are representative of three independent experiments

p65 subunit of NF-KB at Lys310, subsequently inhibiting the transcriptional activity of NF-KB [52]. IKK $\beta$ phosphorylates the p65 subunit of NF-KB in the cytosol, while SIRT deacetylates the p65 subunit of NF-KB in the nucleus [53]. AMPK also phosphorylates the transcription factor peroxisome proliferatoractivated receptor $\gamma$ co-activator $1 a$, which directly interacts with the p65 subunit of NF-KB in the nucleus [54]. In the present study, 2HG activated AMPK by altering the ATP/ADP ratio and suppressing the phosphorylation of $I K K a / \beta$ and $I K B a$, suggesting that the AMPK/SIRT and AMPK/PGC-1a pathways, which function in the nucleus, are not involved in the inhibitory effect of $2 \mathrm{HG}$ on IKK activation. Previously, AMPK activators were shown to inhibit TNF-a-induced IKK activation [55] and reduce the LPSinduced expression of proinflammatory genes by inhibiting IKK activity [56]; AMPK activation inhibits the glycolysis-mediated Olinked $N$-acetylglucosamine modification of IKK $\beta$ at serine 733 , resulting in reduced IKK $\beta$ activity through the phosphorylation of p53 $[57,58]$. We further found that $2 \mathrm{HG}$ inhibited LPS-induced aerobic glycolysis without altering O-linked $\mathrm{N}$-acetyl-glucosamine modification of IKK $\beta$ in LPS-activated BV-2 microglial cells (data not shown). Moreover, since LPS-induced aerobic glycolysis occurs after the transcriptional activation of NF-KB or HIF1 signaling [59], the AMPK/p53/glycolysis pathway seems unlikely to be involved in the suppressive effect of $2 \mathrm{HG}$ on IKK activation. Based on these results, other cytosolic mechanisms mediate the inhibitory effects of $2 \mathrm{HG}$ on NF-KB signaling.

mTOR, a downstream signaling effector in the AMPK pathway, plays important roles in cell metabolism and inflammation [60]. AMPK inhibits mTOR signaling by directly phosphorylating TSC2 and the mTORC1 component Raptor [60]. Notably, mTOR positively regulates NF-KB-dependent gene expression by interacting with the IKK complex in prostate cancer cells [61], and the mTOR inhibitor rapamycin suppresses the production of proinflammatory factors in LPS-activated microglial cells by inhibiting the NF-KB signaling pathway $[62,63]$. Consistent with these results, we confirmed that rapamycin significantly inhibited LPSinduced microglial proinflammatory gene expression by abolishing IKK activation. Moreover, 2HG inhibited the LPS-induced activation of mTOR signaling, accompanied by the inhibition of microglial activation and IKK phosphorylation. Previously, the accumulation of $2 \mathrm{HG}$ was shown to decrease mTOR signaling by inhibiting ATP synthase in glioma cells [41]. In the present study, we also confirmed that $2 \mathrm{HG}$ decreased the OCR and the ATP/ADP ratio in microglial cells. However, another study reported the opposite results and revealed that the production of $2 \mathrm{HG}$ induced by the IDH1/2 mutation activated mTOR signaling by inhibiting the a-KG-dependent enzyme KDM4A in glioma cells [64]. Nevertheless, the current study indicated that mTOR inhibition 
CJ Han et al.
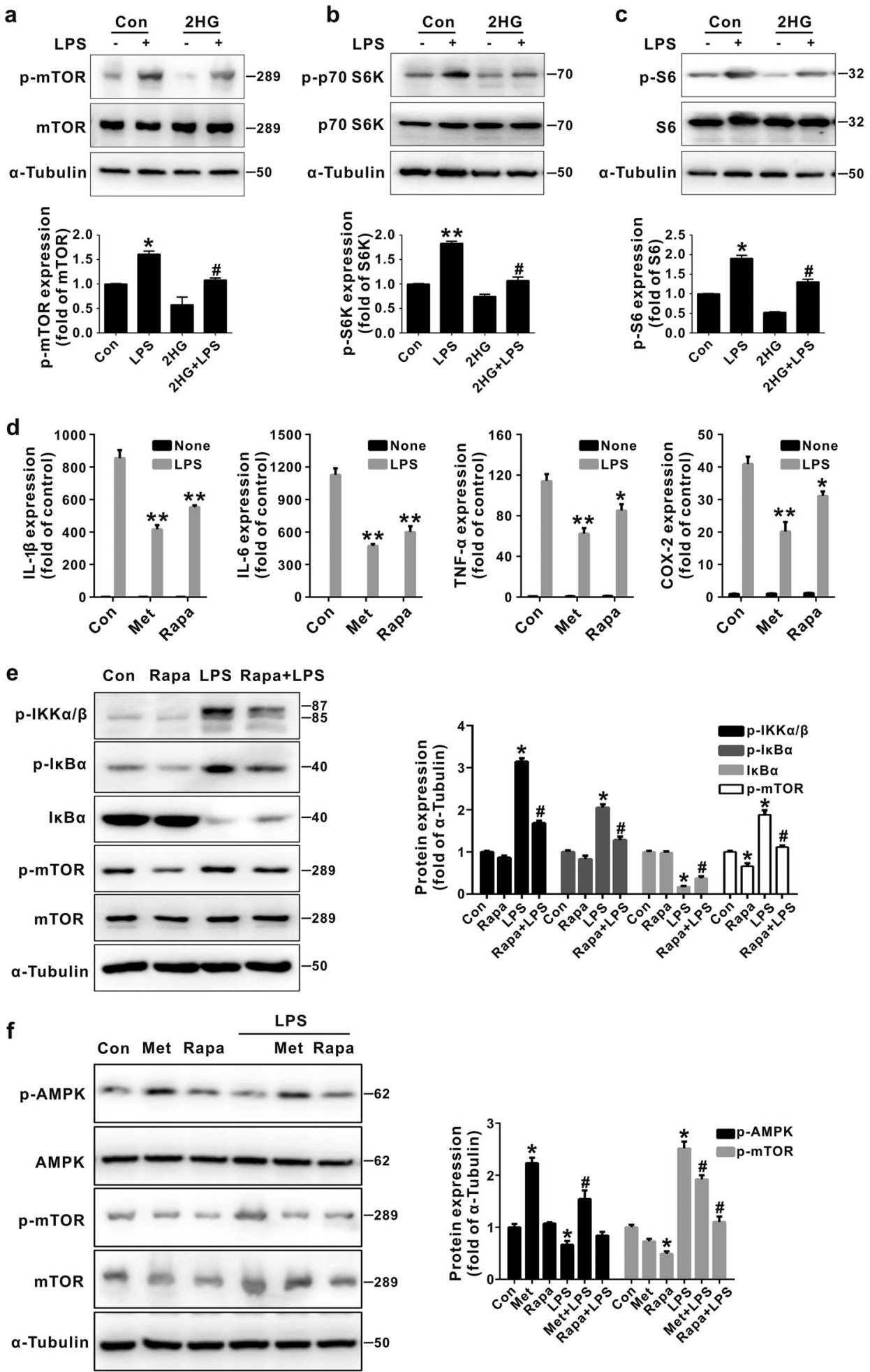

Fig. 6 2-Hydroxyglutarate (2HG) decreases mammalian target of rapamycin (mTOR) signaling in BV-2 microglial cells. a-c BV-2 cells were incubated with lipopolysaccharide (LPS) $(100 \mathrm{ng} / \mathrm{mL})$ for the indicated times after a $30 \mathrm{~min} 2 \mathrm{HG}(1 \mathrm{mM})$ pretreatment. The levels of the indicated phosphorylated ( $p-)$ and total proteins were analyzed using Western blotting. ${ }^{*} P<0.05$ and ${ }^{* *} P<0.01$ compared to Con; ${ }^{\#} P<0.05$ compared to LPS. (d) After pretreatments with $2 \mathrm{mM}$ metformin (Met) and $100 \mathrm{nM}$ rapamycin (Rapa), cells were incubated with LPS for $6 \mathrm{~h}$. The expression of the IL-1 $\beta$, IL- 6 , TNF- $\alpha$ and COX-2 mRNAs was measured using quantitative real-time PCR (qPCR), and glyceraldehyde 3phosphate dehydrogenase (GAPDH) was used as the internal control. ${ }^{*} P<0.05$ and ${ }^{* *} P<0.01$ compared to Con + LPS. e Cells were pretreated

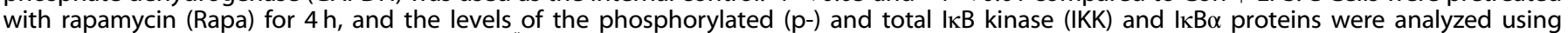
Western blotting. ${ }^{*} P<0.05$ compared to Con. ${ }^{\#} P<0.05$ compared to LPS. $\mathbf{f}$ Metformin (Met) and rapamycin (Rapa) were added to the culture for 12 or $4 \mathrm{~h}$, and then the levels of the phosphorylated ( $\mathrm{p}-$ ) and total adenosine $5^{\prime}$-monophosphate-activated protein kinase (AMPK) and mTOR proteins were analyzed using Western blotting. The levels of all indicated proteins were quantified using densitometry and normalized to $\alpha$-tubulin. ${ }^{*} P<0.05$ compared to Con. ${ }^{\#} P<0.05$ compared to LPS. All results are presented as the means \pm SD $(n=3)$ and are representative of three independent experiments 


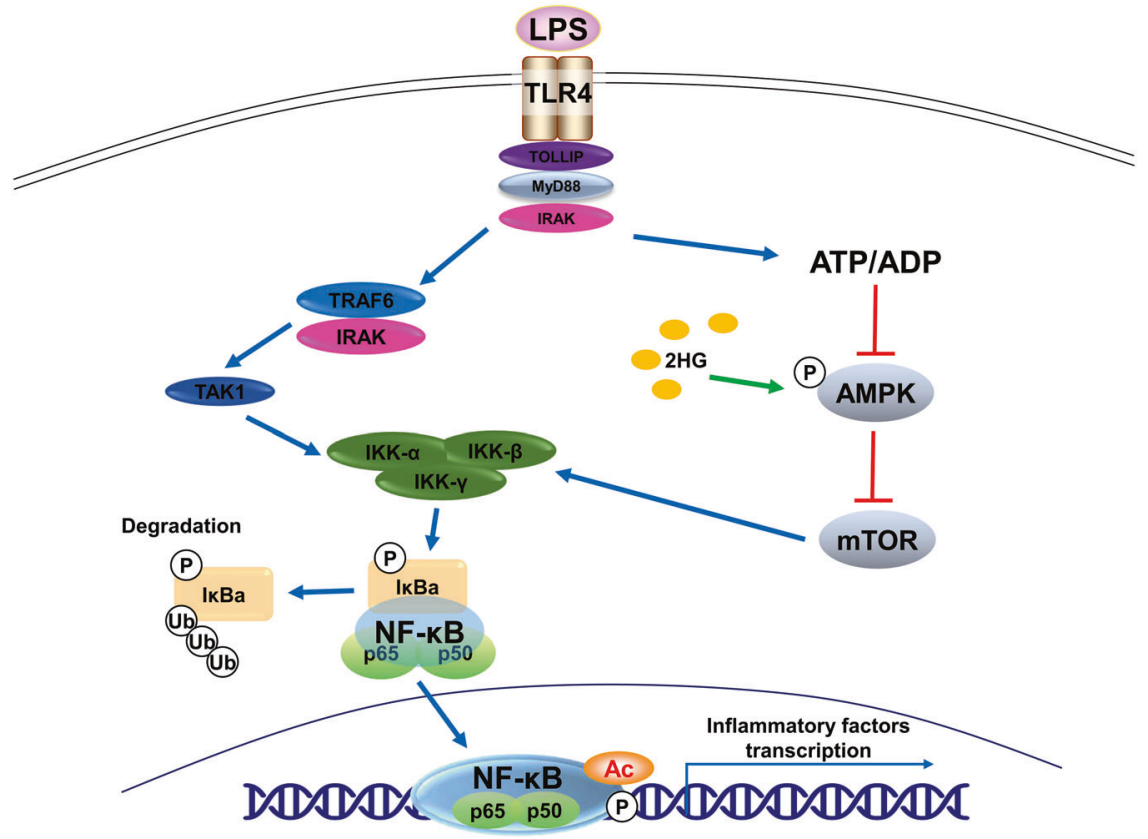

Fig. 7 Schematic showing the potential mechanisms underlying the anti-inflammatory effects of 2-hydroxyglutarate (2HG). Lipopolysaccharide (LPS)-induced activation of toll-like receptor 4 (TLR4) triggers IKB kinase $\beta$ (IKK $\beta$ ) activation through the ubiquitination of TNF receptor associated factor 6 (TRAF6) and phosphorylation of TGF- $\beta$ activated kinase (TAK). Activation of IKK $\beta$ leads to the phosphorylation and

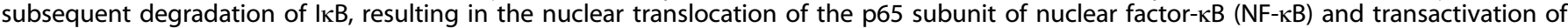
target genes. $2 \mathrm{HG}$ increases adenosine $5^{\prime}$-monophosphate-activated protein kinase (AMPK) phosphorylation and decreases mammalian target of rapamycin (mTOR) phosphorylation by suppressing mitochondrial oxidative phosphorylation, ultimately blocking LPS-induced IKK $\alpha / \beta$ phosphorylation and NF- $\mathrm{KB}$ transcriptional activity

mediated by AMPK activation appeared to be involved in the inhibitory effect of $2 \mathrm{HG}$ on inflammatory responses and IKK activation.

In summary, (i) the oncometabolite 2HG inhibits CM-, LPS-, and TNF-a-induced inflammatory activation of microglia by inhibiting IKK activation. (ii) Activation of AMPK and subsequent mTOR inhibition are involved in the anti-inflammatory mechanisms of $2 \mathrm{HG}$. Although the translational benefit of $2 \mathrm{HG}$ in patients with glioma must be further elucidated, our study provides a molecular and cellular basis for the function of $2 \mathrm{HG}$ in microglial cells in the brain.

\section{ACKNOWLEDGEMENTS}

This study was supported in part by grants from the National Natural Science Foundation of China $(81372688,81373382,81773702,81773561$, and 81130023) and the Priority Academic Program Development of the Jiangsu Higher Education Institutes (PAPD)

\section{AUTHOR CONTRIBUTIONS}

XCZ and LTZ designed the research; CJH, JYZ, LS, HCY and ZQC performed the experiments; CJH and LTZ analyzed the data; and CJH, LTZ, XCZ, XHZ wrote the paper.

\section{ADDITIONAL INFORMATION}

The online version of this article (https://doi.org/10.1038/s41401-019-0225-9) contains supplementary material, which is available to authorized users.

Competing interests: The authors declare no competing interests.

\section{REFERENCES}

1. Furnari FB, Fenton T, Bachoo RM, Mukasa A, Stommel JM, Stegh A, et al. Malignant astrocytic glioma: genetics, biology, and paths to treatment. Genes Dev. 2007;21:2683-710.
2. Holland EC. Glioblastoma multiforme: the terminator. Proc Natl Acad Sci USA 2000;97:6242-4.

3. Charles NA, Holland EC, Gilbertson R, Glass R, Kettenmann H. The brain tumor microenvironment. Glia. 2012;60:502-14.

4. Hambardzumyan D, Gutmann DH, Kettenmann $\mathrm{H}$. The role of microglia and macrophages in glioma maintenance and progression. Nat Neurosci. 2016;19:20-7.

5. Gabrusiewicz K, Ellert-Miklaszewska A, Lipko M, Sielska M, Frankowska M, Kaminska B. Characteristics of the alternative phenotype of microglia/ macrophages and its modulation in experimental gliomas. PLoS One. 2011;6: e23902.

6. Domingues $P$, Gonzalez-Tablas M, Otero A, Pascual D, Miranda D, Ruiz L, et al. Tumor infiltrating immune cells in gliomas and meningiomas. Brain Behav Immun. 2016:53:1-15.

7. Zhai H, Heppner FL, Tsirka SE. Microglia/macrophages promote glioma progression. Glia. 2011;59:472-85.

8. Saijo K, Glass CK. Microglial cell origin and phenotypes in health and disease. Nat Rev Immunol. 2011;11:775-87.

9. Umemura N, Saio M, Suwa T, Kitoh Y, Bai J, Nonaka K, et al. Tumor-infiltrating myeloid-derived suppressor cells are pleiotropic-inflamed monocytes/macrophages that bear M1- and M2-type characteristics. J Leukoc Biol. 2008;83:1136-44.

10. Li W, Graeber MB. The molecular profile of microglia under the influence of glioma. Neuro Oncol. 2012;14:958-78.

11. Markovic DS, Vinnakota K, Chirasani S, Synowitz M, Raguet $H$, Stock K, et al. Gliomas induce and exploit microglial MT1-MMP expression for tumor expansion. Proc Natl Acad Sci USA 2009;106:12530-5.

12. Sica A, Schioppa T, Mantovani A, Allavena P. Tumour-associated macrophages are a distinct M2 polarised population promoting tumour progression: potential targets of anti-cancer therapy. Eur J Cancer. 2006;42:717-27.

13. Ye XZ, Xu SL, Xin YH, Yu SC, Ping YF, Chen L, et al. Tumor-associated microglia/ macrophages enhance the invasion of glioma stem-like cells via TGF-beta1 signaling pathway. J Immunol. 2012;189:444-53.

14. Wu SY, Watabe $\mathrm{K}$. The roles of microglia/macrophages in tumor progression of brain cancer and metastatic disease. Front Biosci. 2017;22:1805-29.

15. Ransohoff RM. A polarizing question: do M1 and M2 microglia exist? Nat Neurosci. 2016;19:987-91.

16. Szulzewsky F, Pelz A, Feng X, Synowitz M, Markovic D, Langmann T, et al. Gliomaassociated microglia/macrophages display an expression profile different from 
M1 and M2 polarization and highly express Gpnmb and Spp1. PLoS One. 2015;10: e0116644.

17. Yan H, Parsons DW, Jin G, McLendon R, Rasheed BA, Yuan W, et al. IDH1 and IDH2 mutations in gliomas. N Engl J Med. 2009;360:765-73.

18. Mardis ER, Ding L, Dooling DJ, Larson DE, McLellan MD, Chen K, et al. Recurring mutations found by sequencing an acute myeloid leukemia genome. $\mathrm{N}$ Engl J Med. 2009;361:1058-66.

19. Parsons DW, Jones $S$, Zhang $X$, Lin JC, Leary RJ, Angenendt $P$, et al. An integrated genomic analysis of human glioblastoma multiforme. Science. 2008;321:1807-12.

20. Dang L, White DW, Gross S, Bennett BD, Bittinger MA, Driggers EM, et al. Cancerassociated IDH1 mutations produce 2-hydroxyglutarate. Nature. 2009;462: 739-44.

21. Xiao M, Yang $H$, Xu W, Ma S, Lin H, Zhu H, et al. Inhibition of alpha-KG-dependent histone and DNA demethylases by fumarate and succinate that are accumulated in mutations of FH and SDH tumor suppressors. Genes Dev. 2012;26:1326-38.

22. Xu W, Yang H, Liu Y, Yang Y, Wang P, Kim SH, et al. Oncometabolite 2hydroxyglutarate is a competitive inhibitor of alpha-ketoglutarate-dependent dioxygenases. Cancer Cell. 2011;19:17-30.

23. Fathi AT, Nahed BV, Wander SA, lafrate AJ, Borger DR, Hu R, et al. Elevation of urinary 2-hydroxyglutarate in IDH-mutant glioma. Oncologist. 2016;21:214-9.

24. Fathi AT, Sadrzadeh $H$, Comander AH, Higgins MJ, Bardia A, Perry A, et al. Isocitrate dehydrogenase 1 (IDH1) mutation in breast adenocarcinoma is associated with elevated levels of serum and urine 2-hydroxyglutarate. Oncologist. 2014;19:602-7.

25. Fathi AT, Sadrzadeh H, Borger DR, Ballen KK, Amrein PC, Attar EC, et al. Prospective serial evaluation of 2-hydroxyglutarate, during treatment of newly diagnosed acute myeloid leukemia, to assess disease activity and therapeutic response. Blood. 2012;120:4649-52.

26. Pellegatta S, Valletta L, Corbetta C, Patane M, Zucca I, Riccardi Sirtori F, et al. Effective immuno-targeting of the IDH1 mutation $\mathrm{R} 132 \mathrm{H}$ in a murine model of intracranial glioma. Acta Neuropathol Commun. 2015;3:4.

27. Amankulor NM, Kim Y, Arora S, Kargl J, Szulzewsky F, Hanke M, et al. Mutant IDH1 regulates the tumor-associated immune system in gliomas. Genes Dev. 2017;31:774-86.

28. Kohanbash G, Carrera DA, Shrivastav S, Ahn BJ, Jahan N, Mazor T, et al. Isocitrate dehydrogenase mutations suppress STAT1 and $\mathrm{CD}^{+}$T cell accumulation in gliomas. J Clin Invest. 2017;127:1425-37.

29. Lu C, Ward PS, Kapoor GS, Rohle D, Turcan S, Abdel-Wahab O, et al. IDH mutation impairs histone demethylation and results in a block to cell differentiation. Nature. 2012;483:474-8.

30. Giulian D, Baker TJ. Characterization of ameboid microglia isolated from developing mammalian brain. J Neurosci. 1986;6:2163-78.

31. Tao L, Zhang F, Hao L, Wu J, Jia J, Liu JY, et al. 1-O-tigloyl-1-O-deacetyl-nimbolinin $B$ inhibits LPS-stimulated inflammatory responses by suppressing NF-kappaB and JNK activation in microglia cells. J Pharmacol Sci. 2014;125:364-74.

32. Guo DK, Zhu Y, Sun HY, Xu XY, Zhang S, Hao ZB, et al. Pharmacological activation of REV-ERBalpha represses LPS-induced microglial activation through the NFkappaB pathway. Acta Pharmacol Sin. 2019;40:26-34.

33. Xu Z, Wu J, Zheng J, Ma H, Zhang $H$, Zhen $X$, et al. Design, synthesis and evaluation of a series of non-steroidal anti-inflammatory drug conjugates as novel neuroinflammatory inhibitors. Int J Immunopharmacol. 2015;25:528-37.

34. Zhou X, Gan P, Hao L, Tao L, Jia J, Gao B, et al. Antiinflammatory effects of orientin-2"-O-galactopyranoside on lipopolysaccharide-stimulated microglia. Biol Pharm Bull. 2014;37:1282-94.

35. Zhang $L$, Yang $H$, Zhang $W$, Liang $Z$, Huang $Q$, Xu G, et al. Clk1-regulated aerobic glycolysis is involved in glioma chemoresistance. J Neurochem. 2017;142:574-88.

36. Choi C, Ganji SK, DeBerardinis RJ, Hatanpaa KJ, Rakheja D, Kovacs Z, et al. 2hydroxyglutarate detection by magnetic resonance spectroscopy in IDH-mutated patients with gliomas. Nat Med. 2012;18:624-9.

37. Linninger A, Hartung GA, Liu BP, Mirkov S, Tangen K, Lukas RV, et al. Modeling the diffusion of $\mathrm{D}$-2-hydroxyglutarate from IDH1 mutant gliomas in the central nervous system. Neuro Oncol. 2018;20:1197-206.

38. Zheng PP, van der Weiden M, van der Spek PJ, Vincent AJ, Kros JM. Isocitrate dehydrogenase $1 \mathrm{R} 132 \mathrm{H}$ mutation in microglia/macrophages in gliomas: indication of a significant role of microglia/macrophages in glial tumorigenesis. Cancer Biol Ther. 2012;13:836-9.

39. Chen JY, Lai YS, Tsai HJ, Kuo CC, Yen BL, Yeh SP, et al. The oncometabolite R-2hydroxyglutarate activates NF-kappaB-dependent tumor-promoting stromal niche for acute myeloid leukemia cells. Sci Rep. 2016;6:32428.

40. Bottcher M, Renner K, Berger R, Mentz K, Thomas S, Cardenas-Conejo ZE, et al. D2-hydroxyglutarate interferes with HIF-1alpha stability skewing T-cell metabolism towards oxidative phosphorylation and impairing Th17 polarization. Oncoimmunology. 2018;7:e1445454.
41. Fu X, Chin RM, Vergnes L, Hwang H, Deng G, Xing Y, et al. 2-Hydroxyglutarate Inhibits ATP Synthase and mTOR ignaling. Cell Metab. 2015;22:508-15.

42. Mancini SJ, White AD, Bijland S, Rutherford C, Graham D, Richter EA, et al. Activation of AMP-activated protein kinase rapidly suppresses multiple proinflammatory pathways in adipocytes including IL-1 receptor-associated kinase4 phosphorylation. Mol Cell Endocrinol. 2017;440:44-56.

43. Gao Y, Gartenhaus RB, Lapidus RG, Hussain A, Zhang Y, Wang X, et al. Differential IKK/NF-kappaB activity is mediated by TSC2 through mTORC1 in PTEN-null prostate cancer and tuberous sclerosis complex tumor cells. Mol Cancer Res. 2015;13:1602-14.

44. Sahan-Firat S, Temiz-Resitoglu M, Guden DS, Kucukkavruk SP, Tunctan B, Sari AN, et al. Protection by mTOR inhibition on zymosan-induced systemic inflammatory response and oxidative/nitrosative stress: contribution of mTOR/MEK1/ERK1/2/IKKbeta/lkappaB-alpha/NF-kappaB signalling pathway. Inflammation. 2018;41:276-98.

45. Houillier C, Wang X, Kaloshi G, Mokhtari K, Guillevin R, Laffaire J, et al. IDH1 or IDH2 mutations predict longer survival and response to temozolomide in lowgrade gliomas. Neurology. 2010;75:1560-6.

46. Tran AN, Lai A, Li S, Pope WB, Teixeira S, Harris RJ, et al. Increased sensitivity to radiochemotherapy in $\mathrm{IDH} 1$ mutant glioblastoma as demonstrated by serial quantitative MR volumetry. Neuro Oncol. 2014;16:414-20.

47. Molenaar RJ, Botman D, Smits MA, Hira VV, van Lith SA, Stap J, et al. Radioprotection of IDH1-mutated cancer cells by the IDH1-mutant inhibitor AGI-5198. Cancer Res. 2015;75:4790-802.

48. Baldewpersad Tewarie NM, Burgers IA, Dawood Y, den Boon HC, den Brok MG, Klunder $\mathrm{JH}$, et al. NADP+dependent IDH1 R132 mutation and its relevance for glioma patient survival. Med Hypotheses. 2013;80:728-31.

49. Bunse $L$, Pusch S, Bunse T, Sahm F, Sanghvi K, Friedrich $M$, et al. Suppression of antitumor $\mathrm{T}$ cell immunity by the oncometabolite $(R)$-2-hydroxyglutarate. Nat Med. 2018;24:1192-203.

50. Liu T, Zhang L, Joo D, Sun SC. NF-kappaB signaling in inflammation. Signal Transduct Target Ther 2017;2:e17023.

51. Salminen A, Hyttinen JM, Kaarniranta K. AMP-activated protein kinase inhibits NFkappaB signaling and inflammation: impact on healthspan and lifespan. J Mol Med. 2011;89:667-76.

52. Canto C, Gerhart-Hines Z, Feige JN, Lagouge M, Noriega L, Milne JC, et al. AMPK regulates energy expenditure by modulating $\mathrm{NAD}^{+}$metabolism and SIRT1 activity. Nature. 2009;458:1056-60.

53. Kiernan R, Bres V, Ng RW, Coudart MP, El Messaoudi S, Sardet C, et al. Postactivation turn-off of NF-kappa B-dependent transcription is regulated by acetylation of p65. J Biol Chem. 2003;278:2758-66.

54. Alvarez-Guardia D, Palomer X, Coll T, Davidson MM, Chan TO, Feldman AM, et al. The p65 subunit of NF-kappaB binds to PGC-1alpha, linking inflammation and metabolic disturbances in cardiac cells. Cardiovasc Res. 2010;87:449-58.

55. Hattori Y, Suzuki K, Hattori S, Kasai K. Metformin inhibits cytokine-induced nuclear factor kappaB activation via AMP-activated protein kinase activation in vascular endothelial cells. Hypertension. 2006:47:1183-8.

56. Giri S, Nath N, Smith B, Viollet B, Singh AK, Singh I. 5-aminoimidazole-4-carboxamide-1-beta-4-ribofuranoside inhibits proinflammatory response in glial cells: a possible role of AMP-activated protein kinase. J Neurosci. 2004;24: 479-87.

57. Kawauchi K, Araki K, Tobiume K, Tanaka N. p53 regulates glucose metabolism through an IKK-NF-kappaB pathway and inhibits cell transformation. Nat Cell Biol. 2008;10:611-8.

58. Kawauchi K, Araki K, Tobiume K, Tanaka N. Loss of p53 enhances catalytic activity of IKKbeta through O-linked beta-N-acetyl glucosamine modification. Proc Natl Acad Sci USA 2009;106:3431-6.

59. Cheng SC, Quintin J, Cramer RA, Shepardson KM, Saeed S, Kumar V, et al. mTORand HIF-1alpha-mediated aerobic glycolysis as metabolic basis for trained immunity. Science. 2014;345:1250684.

60. Mihaylova MM, Shaw RJ. The AMPK signalling pathway coordinates cell growth, autophagy and metabolism. Nat Cell Biol. 2011;13:1016-23.

61. Dan HC, Cooper MJ, Cogswell PC, Duncan JA, Ting JP, Baldwin AS. Akt-dependent regulation of NF-\{kappa\}B is controlled by mTOR and Raptor in association with IKK. Genes Dev. 2008;22:1490-500.

62. Han HE, Kim TK, Son HJ, Park WJ, Han PL. Activation of autophagy pathway suppresses the expression of iNOS, IL6 and cell death of LPS-stimulated microglia cells. Biomol Ther. 2013;21:21-8.

63. Ye J, Jiang Z, Chen X, Liu M, Li J, Liu N. The role of autophagy in pro-inflammatory responses of microglia activation via mitochondrial reactive oxygen species in vitro. J Neurochem. 2017;142:215-30.

64. Carbonneau M, Gagné LM, Lalonde ME, Germain MA, Motorina A, Guiot MC, et al. The oncometabolite 2-hydroxyglutarate activates the mTOR signalling pathway. Nat Commun. 2016;7:12700. 